\title{
EPILEPSIA REFRATÁRIA NA INFÂNCIA
}

\author{
LUUCIA FONTENEUL*", VANESSA KREIMER**
}

RESUMO - Uma série de síndromes epilépticas infantis de prognósticos desfavoráveis quanto ao controle das crises, quando estudada, revela aspectos comuns que permitem delimitar um perfil clínico para as epilepsias refratárias. As autoras analisam as intemaçōes realizadas na enfermaria de crianças do Instituto de Neurologia Deolindo Couto da Universidade Federal do Rio de Janeiro, num período de dois anos, para tratamento de crises convulsivas e concluem que a maioria dos casos enquadrava-se no perfil clínico das epilepsias refratárias.

PALAVRAS-CHAVE: epilepsia, refratária, resistente, intratável.

\section{Refractory epilepsy in chidhood}

SUMMARY - The study of epileptic syndromes in childrens displaying a poor prognosis reveals common characteristics which allow the delineation of a clinical profile. In this study, hospital records of a treatment of convulsions in children were analysed during a two year period. We observed that the majority of cases presented this clinical profile.

KEY WORDS: epilepsy, refractory, severe, intractable.

Um grupo de síndromes convulsivas infantis de prognósticos desfavoráveis quanto ao controle das crises, ao ser analisado, revela aspectos comuns que permitem delimitar um perfil clínico para as epilepsias refratárias desta faixa etária: início das crises nos primeiros anos de vida; participação concomitante de vários tipos de crise; observação de sinais e sintomas denotativos de comprometimento do sistema nervoso - que podem anteceder ou suceder ao quadro epiléptico; e presença de anormalidades significativas no eletrencefalograma (EEG). A verificação destas características numa criança que apresenta convulsões recorrentes pressupõe uma resposta insatisfatória ao tratamento com drogas antiepilépticas (DAE).

Neste estudo foram analisadas, retrospectivamente, 68 internaçōes hospitalares de 51 crianças que apresentavam crises convulsivas, visando a identificar os casos nos quais estavam presentes as características que definem o perfil clínico das epilepsias refratárias.

\section{CASUISTICA}

No periodo de 12-fevereiro-1990 a 3-fevereiro-1992 foram intemadas 54 crianças para tratamento de convulsōes, na Enfermaria de Neuropediatria do INDC-UFRJ. Três delas foram exclufdas do estudo porque a observaçāo hospitalar mostrou que as manifestações clínicas não eram de natureza epiléptica. Trinta e nove foram hospitalizadas uma única vez, 11 internadas por duas vezes, uma em três ocasiðes e uma criança necessitou de 4 hospitalizaçðes, perfazendo o total de 68 internaçð̃es.

*Professora Adjunta de Neurologia da Universidade Federal do Rio de Janeiro (UFRJ), Chefe do Setor de Neuropediatria do Instituto de Neurologia Deolindo Couto (INDC-UFRJ); ** Médica do Setor de Neuropediatria do INDC-UFRJ. Aceite: 21 -julho-1994.

Dra. Lúcia Fontenelle - Rua Sorocaba,464 Gr 302 - 22271-110 Rio de Janeiro RJ - Brasil. 
O tempo médio das internaçð̄es foi 9 dias (1-49). Trinta e quatro pacientes $(66,67 \%)$ pertenciam ao sexo masculino e $17(33,33 \%)$ ao feminino.

As convulsőes iniciaram-se no periodo neonatal em 9 crianças $(17,64 \%)$, até os 12 meses de idade em 22 pacientes $(43,13 \%)$, entre os 13 meses e os 6 anos completos em $16(31,37 \%)$, e após esta idade até os 14 anos em 3 crianças (5,88\%). Em um caso nāo foi possível obter informaçð̃es quanto ao inf́cio das crises.

Trinta e um pacientes $(60,78 \%)$ apresentavam crises mistas, sendo considerado como tais a associação de mais de um tipo de crise generalizada ou a combinação de crises generalizadas com parciais. Treze crianças $(25,50 \%)$ sofriam de crises generalizadas isoladas, sendo que 8 tinham convulsões tônico clônicas, três - crises mioclônicas, uma apresentava crises tónicas e uma crises atônicas. $O$ quadro clínico de 7 pacientes $(13,72 \%)$ caracterizava-se por crises parciais: 5 complexas; uma simples e uma com generalizaçăo secundária.

As crises convulsivas foram consideradas como sintomáticas em 33 pacientes $(64,70 \%)$, sendo associadas a encefalopatia não progressiva em 23 casos, a encefalopatia progressiva de etiologia não esclarecida em 3 casos e a esclerose tuberosa em um caso. Seis crianças apresentavam síndrome de West secundária. Em 18 crianças $(35,30 \%)$ não foram encontradas alteraçőes que justificassem o diagnóstico de crises sintomáticas - as histórias gestacional, fisiológica e patologica pregressas caracterizavam-se pela falta de informaçōes significativas para o diagnóstico de encefalopatia. Este grupo foi classificado como portador de epilepsia primária. Foi possivel identificar, neste grupamento de pacientes, 3 casos de sindrome de Lennox-Gastaut e um caso de síndrome de Landau-Kleffner.

Das 68 internaçðes, $48(70,58 \%)$ foram motivadas por crises que se repetiam diariamente - uma ou mais vezes; $5(7,35 \%)$ por mais de uma crise semanal; e duas $(2,94 \%)$ por crises que se manifestavam semanalmente. Em duas internaçôes $(2,94 \%)$ os fenômenos epilépticos ocorriam numa frequência variável. Uma internaçăo $(1,47 \%)$ foi determinada por estado de mal epiléptico. Duas hospitalizações $(2,94 \%)$ foran secundárias a crise única e no prontuário de 8 internaçōes $(11,76 \%)$ não constava a periodicidade das manifestações clínicas.

Quarenta e dois pacientes $(82,35 \%)$ tinham EEGs anormais. Em 5 casos $(9,80 \%)$ os traçados năo mostravam alteraçðes e em outros $4(7,85 \%)$ o exame não foi realizado. Vinte e duas crianças $(43,13 \%)$ foram submetidas a investigaçăo tomográfica computadorizada do crânio que se revelou anormal em 10.

Em 62 internaçōes $(91,17 \%)$ as crianças foram hospitalizadas já em uso de DAE - monoterapia em 26 e politerapia em 36. Apenas em 4 hospitalizaçðes $(5,88 \%)$ os pacientes nåo estavam sendo tratados, previamente, com drogas especfficas. Em dois prontuários $(2,94 \%)$ não havia anotaçð̄es quanto ao tratamento anterior a internaçăo.

Durante as 68 internaçð̃es foi possível utilizar monoterapia em 31 oportunidades (45,58\%). Em 35 $(51,47 \%)$ prescreveu-se mais do que um anticonvulsivante. Cortrosina ou corticơide - isolados ou em combinação com DAE - foram inevitáveis em 11 hospitalizaçōes $(16,17 \%)$. Em duas internações $(4,41 \%)$ não foram usadas drogas especificas.

A alta hospitalar foi dada com os pacientes assintomáticos em 19 oportunidades $(27,94 \%)$, melhorados mas ainda apresentando crises em 41 ocasiōes $(60,29 \%)$ e com o quadro epiléptico inalterado em duas $(2,94 \%)$. Em 6 altas $(8,82 \%)$ não havia menção da condiçăo do paciente.

\section{COMENTÁRIOS}

$\mathrm{Na}$ maioria das vezes, tratar uma criança epiléptica nāo constitue problema. A escolha da droga indicada, em doses terapêutica e sérica adequadas, costuma produzir controle total ou parcial das manifestaçōes convulsivas. Entretanto, em certo número de casos - cerca de 20 a $30 \%$, segundo alguns autores ${ }^{1,4}$ - as crises repetem-se independentemente do tratamento e da experiência do neuropediatria. Estes casos, ditos refratários ${ }^{3}$, intratáveis' ou resistentes ${ }^{2}$, tornam-se motivo de angústia para os médicos e para os familiares. Para os primeiros, porque os resultados obtidos não atendem às suas expectativas. Para os segundos, porque perdem a esperança da "cura" à medida em que percebem que as sucessivas mudanças de medicamentos não trazem os benefícios esperados.

A partir do conhecimento das síndromes epilépticas infantis é possível identificar aspectos comuns aquelas de caráter refratário. $O$ início precoce, a concomitância de diferentes tipos de crise, 
a presença de lesāo estrutural ou funcional do sistema nervoso e EEGs significativamente alterados são indicativos de mau prognóstico quanto ao controle das crises ${ }^{1,46}$. A identificação deste perfil clínico, numa criança que apresenta crises recorrentes, pode nortear o diagnóstico diferencial entre as epilepsias intratáveis e as inadequadamente tratadas, possibilitando ao médico o pronto reconhecimento de seus limites frente aos casos resistentes.

Neste estudo foram analisadas, retrospectivamente, 68 internações realizadas no INDC-UFRJ, num período de dois anos, para tratamento das crises convulsivas apresentadas por 51 crianças. Esta análise revelou que a maioria dos casos enquadrava-se no perfil clínico que caracteriza as epilepsias refratárias.

As convulsões iniciaram-se antes dos 6 anos de idade em 92,15\% dos casos, sendo que mais da metade da amostra $(60,78 \%)$ sofreu a primeira crise nos primeiros 12 meses de vida. Trinta e uma crianças $(61,77 \%$ ) apresentavam crises mistas e em $66,67 \%$ dos casos foram observados elementos indicativos de comprometimento neurológico. Portanto, a maioria das hospitalizações ocorreu em casos de início precoce, em que estavam presentes mais de um tipo de crise, em crianças com sinais e sintomas de lesão nervosa.

Em 42 pacientes $(82,35 \%)$ os EEGs intercríticos mostravam-se anormais: 29 traçados evidenciavam alterações irritativas e 13 se caracterizavam pelo ritmo de base excessivamente lento. Aicardi' afirma que não só os paroxismos são preditivos das epilepsias resistentes como, também, as anormalidades da atividade de fundo. Sendo assim, o resultado deste conjunto de EEGs se soma as caracteristicas clínicas de grande parte do grupo hospitalizado, na determinação do mau prognóstico quanto ao controle das crises.

Ainda vale a pena citar que a análise dos casos estudados mostrou predomínio do sexo masculino $(66,67 \%)$ sobre o feminino $(33,33 \%)$, fato observado em várias síndromes convulsivas resistentes ${ }^{7}$.

A utilização de politerapia em $51,47 \%$ das hospitalizaçōes e a necessidade de reinternar 13 crianças por outras 29 ocasiōes vêm de encontro ao caráter refratário das convulsões apresentadas pela maioria dos pacientes avaliados.

\section{REFERÊNCIAS}

1. Aicardi J. Clinical approach to the management of intractable epilepsy. Develop Med Child Neurol 1988, 30: $429-440$.

2. Callagham N, Goggin T. Adjuntive therapy in resistant epilepsy. Epilepsia 1988, 29(Suppl 1): 29-35.

3. Dam M. Vigabatrim in refractory epilepsy in adults and its application in children. J Child Neurol 1991, 6 (Suppl 2): S26-S29.

4. Janz D. Neurological morbidity of severe epilepsy. Epilepsia 1988, 29(Suppl 1): 51-58.

5. O'Donohoue NV. Epilepsies of childwood. Ed 2. London: Buterworth, 1985, p 231-235.

6. Reynolds EH. The prevention of chronic epilepsy. Epilepsia 1988, 29(Suppl 1): 525-528.

7. Wallace SF. Seizures in children. In Laidlaw J, Richens A, Oxley J. A textbook of epilepsy. Ed 3. HongKong: Wilture 1988, p 78-143. 